\title{
Apparent predisposition to systemic lupus erythematosus in Chinese patients in West Malaysia
}

\author{
A. O. FRANK* \\ From the Department of Medicine, Faculty of Medicine, University of Malaya, Kuala Lumpur, Malaysia
}

SUMMARY In the first 9 years following the opening of the University Hospital in Kuala Lumpur nearly 130000 patients have been admitted (excluding obstetric patients), and, of these, 175 fulfilled the American Rheumatism Association criteria for the diagnosis of systemic lupus erythematosus. This diagnosis was made significantly more frequently in Chinese patients than in other races. SLE is more often reported from Chinese communities in Asia than from India and tropical Africa. There may be a lower susceptibility to autoimmune disease in black Africans than the suspected increased susceptibility in their American Negro and West Indian descendants. A careful study of racial and geographical factors in autoimmune disease should throw further light on the interaction between the host and his environment which results in autoimmune disease.

Many advances in our understanding of the pathogenesis of systemic lupus erythematosus (SLE) have been made over the last few years, particularly in our understanding of the abnormal immunological responses seen in patients with SLE. Many people, however, believe that these immunological abnormalities are found in predisposed individuals, and this belief has been supported by animal models of SLE in dogs and mice (Talal, 1975), family and twin studies of patients with SLE (Block et al., 1975; Arnett and Shulman, 1976) and the finding that various immunological abnormalities were more frequently found in relatives of patients with SLE than in controls (Larsen, 1972; Chantler et al., 1973; Siegel and Lee, 1973; Lowenstein and Rothfield, 1977).

Three studies have demonstrated that SLE does not occur in the same frequency in patients of different races. Siegel and Lee (1973) and Fessel (1974) both found a higher prevalence of SLE in the American Negro population than in the white population, and the study of 'inbred American tribes' (Morton et al., 1976) found a higher incidence of the disease in some tribes than in others. It seemed reasonable, therefore, to conduct a study of SLE in West Malaysia, where peoples of Malay,

*In conjunction with the SLE Study Group: B. A. Adam, C. G. Beng, S. M. Chu, T. P. Goh, K. S. Lau, C. T. Lee, K. Prathap, S. K. Wan, F. Wang, and J. C. White.

Accepted for publication 4 May 1979.

Correspondence to Dr Frank, Salisbury General Infirmary, Salisbury, Wiltshire, England.
Chinese, and Indian races coexist, to investigate whether SLE occurred with equal frequency in all ethnic groups in the University Hospital, Kuala Lumpur.

\section{Patients and methods}

This study was performed at the University Hospital, Kuala Lumpur, which opened in 1967, and which had had nearly 130000 admissions (excluding obstetric admissions) up to 1 January 1976. At the time of the study it was the only teaching hospital in West Malaysia, and all patients admitted to the hospital were available for study.

In June 1974 the SLE Study Group was formed to continue to study this illness as seen in the University Hospital, as reported previously by Lau and White (1969) and Toh et al. (in press).

An analysis was performed of the number of patients admitted each year for each race, and all records coded with the international classification of disease (World Health Organisation, 1967) no. 734.1 (Lupus erythematosus) were analysed by year of admission. Those fulfilling the ARA criteria (Cohen et al., 1971) were studied.

\section{Results}

Table 1 compares the ethnic composition of the population of patients in University Hospital with the population at large determined by the census of 1970 (Malaysia, 1972). It can be seen that the 
Table 1 Comparison between ethnic groups of the population of West Malaysia (Census, 1970) and SLE patients 1967-October 1976

\begin{tabular}{lllll}
\hline & Malay & Chinese & Indian & Other \\
\hline$\%$ of population & 53.1 & 35.5 & 10.6 & 0.8 \\
$\%$ of SLE patients & 10.4 & 80.7 & 8.4 & 0.5 \\
\hline
\end{tabular}

$\chi^{2}=187 ; \mathrm{P}<0.001$.

Table 2 Comparison of Chinese and Indian and Malay admissions 1967-75 with and without SLE

\begin{tabular}{lrrr}
\hline Race & With SLE & \multicolumn{1}{l}{$\begin{array}{l}\text { Without } \\
\text { SLE }\end{array}$} & Total \\
\hline Chinese & 142 & 66357 & 66499 \\
Indian and Malay & 33 & 59547 & 59580 \\
Total & 175 & 125904 & 126079 \\
\hline
\end{tabular}

$\chi^{2}$ (Yates's correction), 55.569; $\mathrm{P}<0.001$.

Table 3 Comparison of Indian and Malay admissions 1967-75 with and without SLE

\begin{tabular}{llll}
\hline Race & With SLE & $\begin{array}{l}\text { Without } \\
\text { SLE }\end{array}$ & Total \\
\hline Indian & 16 & 36754 & 36770 \\
Malay & 17 & 22793 & 22810 \\
Total & 33 & 59547 & 59580 \\
\hline
\end{tabular}

$\chi^{2}$ (Yates's correction), 1.918; $P>0 \cdot 1$.

hospital population differs greatly from the population at large, and consequently the conclusions from this hospital study cannot reflect the incidence of SLE in the community.

Between 1967 and October 1976, 202 patients were seen in University Hospital with SLE fulfilling the ARA criteria. Chinese patients predominated $(80.7 \%)$, with Malays $10.4 \%$, Indians $8.4 \%$, and others $0.5 \%$. Of these 202 patients 175 presented before 1 January 1976, the period for which control data are available.

Table 2 compares Chinese admissions with and without SLE in the University Hospital between 1967 and 1975 with Indian and Malay admissions over the same period. There was a highly significant difference $(P<0.001)$. Table 3 compares Indian patients with and without SLE with Malay patients with and without SLE over the same period. In this case there was no significant difference.

\section{Discussion}

Support for the hypothesis that SLE could be influenced by racial factors was further sought by reviewing reports of SLE worldwide. Fig. 1 depicts a map of the world with sites of some reports of SLE marked. A number denotes the size of the series. It is noted that SLE has been reported from several places in Asia. Reports from India are rare (Malaviya et al., 1973; Menon et al., 1976), and conflicting views are expressed as to the extent of SLE there. Few patients are actually reported, however, and this contrasts with the reports from the predominantly Chinese communities (in addition to this report) in Hong Kong (Wong, 1969) and Singapore (Tay and Khoo, 1971). A large series has also been described from Japan (Fukase and Ofuzi, 1973) of 689 patients, of whom 275 were thought to fulfil the ARA criteria (Cohen et al., 1971). It may be coincidental, but the infrequent reports from India and the larger reports from Chinese communities also reflect the ethnic composition of this series.

The increased prevalence of SLE in the American Negro has been referred to (see above), and Hughes in Kingston, Jamaica, saw 81 new patients with SLE in 1 year (Hughes, 1977). This contrasts with the 2 patients seen by Greenwood (1968) in a study in Ibadan, Western Nigeria, spanning 9 years. Other reports from equatorial Africa are rare (in contrast to reports from Singapore, which is also near the equator). In South Africa, however, the general feeling that autoimmune disease is seen infrequently in black Africans (O. L. Meyers, personal communication) has been supported by 2 studies (Jessop and Meyers, 1973; Seedat and Pudifin, 1977). Although diagnostic techniques and time to report cases may be scarce in tropical Africa, it is not unreasonable to contrast the reports from Ibadan and Kingston, since both come from teaching centres in the third world. Greenwood (1968) commented that there appears to be a decreased susceptibility to autoimmune disease in West Africa compared to the increased prevalence in the American Negro descendants, and Hughes's (1977) report from Jamaica supports this. If true environmental rather than genetic factors may explain the racial differences. A comparative study of SLE in Japanese people in Japan and in America, or of West Indians in Jamaica and in London might throw further light on this. It is suggested that geographical and racial factors in SLE are worthy of further study.

I am indebted to my colleagues in the Department of Medicine at the University of Malaya for allowing me to study patients under their care, and the unending patience of Mr Lai and the staff of the Medical Records Department for providing me with the data from their statistics and with the records for perusal. I am also indebted to Professor $\mathbf{H}$. $O$. Wong, head of the Department of Medicine, for encouragement, and for the financial support of the University of Malaya through a vote $F$. This work would not have been 


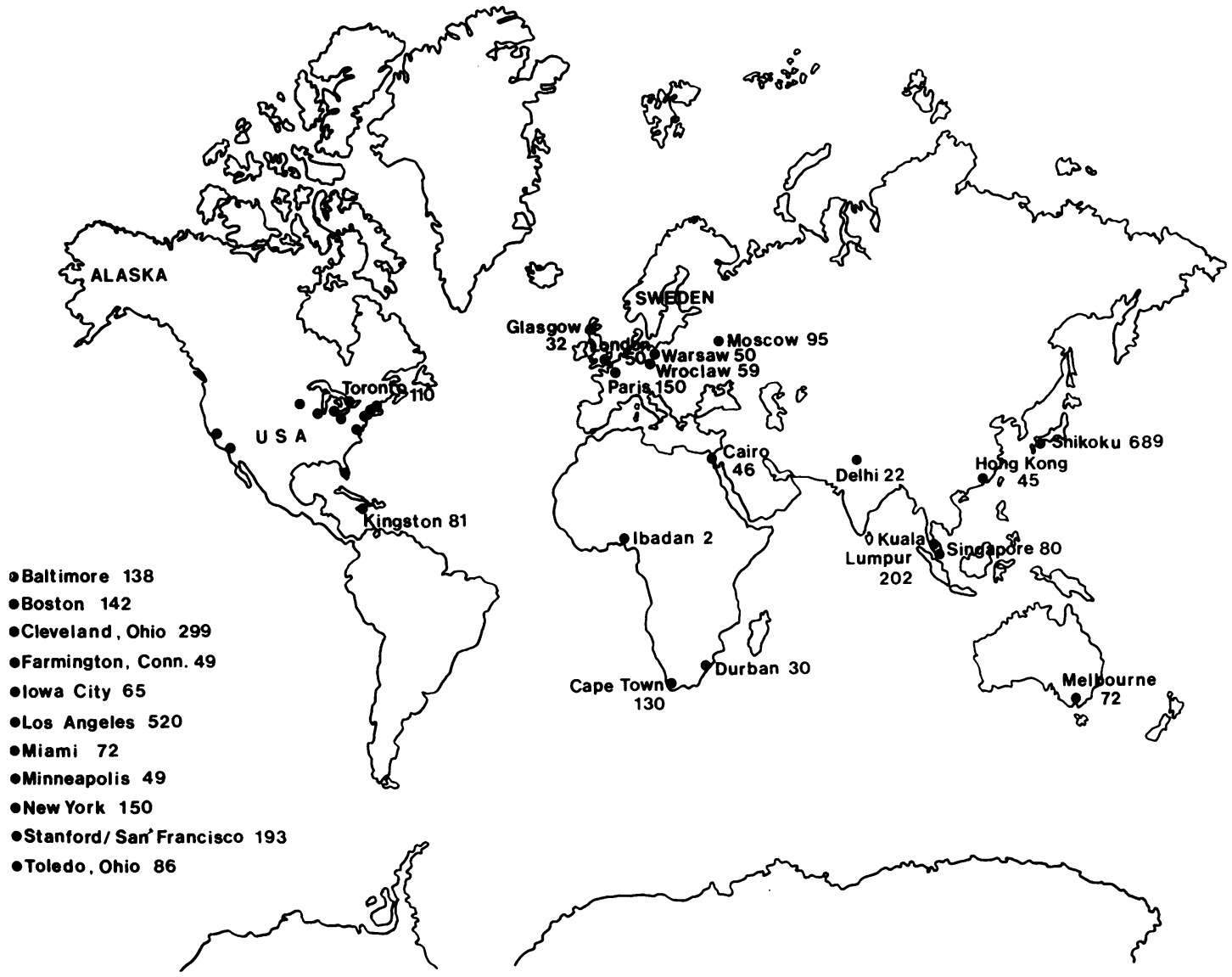

Fig. 1 Sites of some reports of SLE, each number denoting size of report

possible without the help and encouragement of my wife, who personally punched the details of 202 patients on to punch-cards and designed suitable computer analyses. I am also indebted to $\mathrm{Mr} \mathrm{A}$. Cotton from the Department of Community Medicine at Southampton University for making available the facilities of the Department, to Mr John Alexander for continuous guidance on statistical analysis, and to Dr M. I. D. Cawley and Mr John Alexander for criticism of the manuscript. I am also indebted to Mr Bob Gann and Miss Christine Taylor for providing me with the relevant literature and for help in preparing Fig. 1. Finally I thank Mrs Mary Willis for typing the manuscript.

Addendum: The recent findings by Serdula and Rhoads (1979) in an epidemiological study that the Chinese had the highest age adjusted prevalence rate for SLE among the different ethnic groups in Hawaii strongly supports our findings in a hospital population that the Chinese are more prone to SLE than the other racial groups in the study.

\section{References}

Arnett, F. C., and Sulman, L. E. (1976). Studies in familial systemic lupus erythematosus. Medicine, (Baltimore), 55, 313-322.
Block, S. R., Winfield, J. B., Lockshin, M. D., D'Angelo, W. A., and Christian, C. L. (1975). Studies of twins with systemic lupus erythematosus. A review of the literature and presentation of 12 additional sets. American Journal of Medicine, 59, 533-552.

Chantler, S., Hansen, J., Jacobson, J., and Fudenberg, H. H. (1973). Incidence of nuclear antibodies in patients and in related and unrelated groups from a community with a 'micro epidemic' of SLE. Clinical Immunology and Immunopathology, 2, 9-15.

Cohen, A. S., Reynolds, W. E., Franklin, E. C., Kulka, J. P. Ropes, M. W., Shulman, L. E., and Wallace, S. L. (197!). Preliminary criteria for the classification of SLE. Bulletin on the Rheumatic Diseases, 21, 643-648.

Fessel, W. J. (1974). Systemic lupus erythematosus in the community. Incidence, prevalence, outcome and first symptoms, the high prevalence in black women. Archives of Internal Medicine, 134, 1027-1035.

Fukase, M., and Ofuzi, T. (1973). Symposium on autoimmune diseases. (1) Epidemiology of SLE, PSS, and DM in the western part of the Main Island and Skikoku Island in Japan. Japanese Journal of Medicine, 12, 7-10.

Greenwood B. M. (1968). Autoimmune disease and parasite infections in Nigerians. Lancet, 2, 380-382. 
Hughes, G. R. V. (1977). Connective Tissue Diseases, pp. 4-5. Blackwell: Oxford.

Jessop, S., and Meyers, O. L. (1973). Systemic lupus erythematosus in Cape Town. South African Medical Journal, 47, 222-225.

Larsen, R. A. (1972). Family studies in SLE Journal of Chronic Diseases, 25, 187-190.

Lau, K. S., and White, J. C. (1969). Myelosclerosis associated with systemic lupus erythematosus in patients in West Malaysia. Journal of Clinical Pathology, 22, 433-438.

Lowenstein, M. B., and Rothfield, N. F. (1977). Family Study of systemic lupus erythematosus: analysis of the clinical history, skin immunofluorescence, and serologic parameters. Arthritis and Rheumatism, 20, 1293-1303.

Malaviya, A. N., Sethi, L., Bhuyan, U. N., and Kathpalia, S. C. (1973). Diagnosis of systemic lupus erythematosus: changing approach. Journal of the Association of Physicians of India, 21, 1045-1050.

Malaysia (1972). 1970 Population and Housing Census of Malaysia: Community Groups, p. 28. Department of Statistics: Malaysia, Kuala Lumpur.

Menon, N. D., Sharma, N. N., Suri, M. L., and Hoon, R. S. (1976). Systemic lupus erythematosus. Journal of the Association of Physicians of India, 24, 573-578.

Morton, R. O., Gershwin, M. E., Brady, C., and Steinberg, A. D. (1976). The incidence of systemic lupus erythematosus in North American Indians. Journal of Rheumatology, 3, 186-190.
Seedat, Y. K., and Pudifin, D. (1977). Systemic lupus erythematosus in Black and Indian patients in Natal. South African Medical Journal, 51, 335-337.

Serdula, M. K., and Rhoads, G. G. (1979). Frequency of systemic lupus erythematosus in different ethnic groups in Hawaii. Arthritis and Rheumatism, 22, 328-333.

Siegel, M., and Lee, S. L. (1973). The epidemiology of systemic lupus erythematosus. Seminars in Arthritis and Rheumatism, 3, 1-54.

Talal, N. (1975). Animal Models for SLE. Clinics in Rheumatic Diseases, 1, 485-496.

Tay, C. H., and Khoo, O. T. (1971). Systemic lupus erythematosus - an analytic study of eighty cases in Singapore. Singapore Medical Journal, 12, 92-100.

Toh, B. H., Adam, B. A., Beng, C. J., Frank, A. O., Lau, K. S., Lee, C. T., Prathap, K., Wang, F., White, J. C., Goh, T. P., and Wan, S. K. (in press). The pattern of systemic lupus erythematosus in West Malaysia, particularly of haematological manifestations. Journal of the Malaysian Society of Pathologists.

Wong, K. O. (1969). Systemic lupus erythematosus: a report of forty-five cases with unusual clinical and immunological features. British Journal of Dermatology, 81, 186-190.

World Health Organisation (1967). Manual of the International Statistical Classification of Diseases, Injuries and Causes of Death. World Health Organisation: Geneva. 